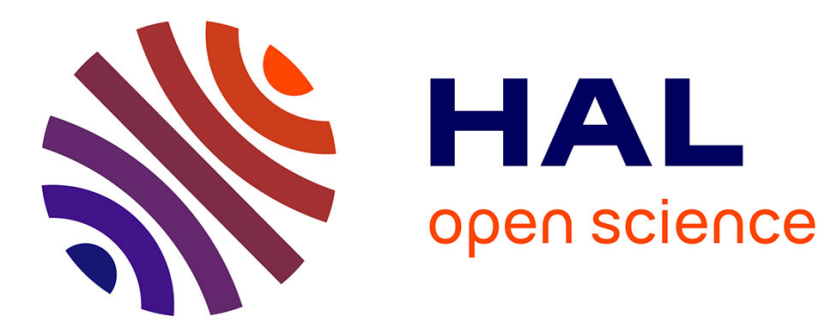

\title{
Two-photon pumped random laser in nanocrystalline $\mathrm{ZnO}$
}

E. V. Chelnokov, N. Bityurin, Igor Ozerov, Wladimir Marine

\section{To cite this version:}

E. V. Chelnokov, N. Bityurin, Igor Ozerov, Wladimir Marine. Two-photon pumped random laser in nanocrystalline ZnO. Applied Physics Letters, 2006, 89 (17), pp.171119. 10.1063/1.2370879 . hal00115824

\section{HAL Id: hal-00115824 \\ https://hal.science/hal-00115824}

Submitted on 18 Oct 2017

HAL is a multi-disciplinary open access archive for the deposit and dissemination of scientific research documents, whether they are published or not. The documents may come from teaching and research institutions in France or abroad, or from public or private research centers.
L'archive ouverte pluridisciplinaire HAL, est destinée au dépôt et à la diffusion de documents scientifiques de niveau recherche, publiés ou non, émanant des établissements d'enseignement et de recherche français ou étrangers, des laboratoires publics ou privés. 


\title{
Two-photon pumped random laser in nanocrystalline $\mathrm{ZnO}$
}

\author{
E. V. Chelnokov and N. Bityurin \\ Institute of Applied Physics Russian Academy of Sciences, 603950 Nizhny Novgorod, Russia \\ I. Ozerov and W. Marine ${ }^{\text {a) }}$ \\ CRMC-N, UPR 7251 CNRS, Campus de Luminy, Case 913, 13288 Marseille Cedex 09, France
}

(Received 28 June 2006; accepted 12 September 2006; published online 27 October 2006)

\begin{abstract}
Thin film of $\mathrm{ZnO}$ nanoparticles with dimension of about 5-10 $\mathrm{nm}$ were fabricated by the pulsed laser ablation method. By using a femtosecond laser beam at $700 \mathrm{~nm}$ to pump micrometer-thick films the authors observed two-photon-induced lasing at $385 \mathrm{~nm}$. Experimentally obtained dependence of the threshold on the excitation spot radius $r_{0}$ is closer to $\left(1 / r_{0}^{2}\right)$ than to $\left(1 / r_{0}\right)$, thus suggesting efficiency of the feedback by scattering-random lasing. The experimental data on nonlinear transmission of the film at the wavelength of pumping are presented. (C) 2006 American Institute of Physics. [DOI: 10.1063/1.2370879]
\end{abstract}

Based on the unique properties of nanoparticles different from bulk material, ${ }^{1,2}$ nanometer-sized structures have shown potential applications in microfabrication, ${ }^{3}$ information technology, and new laser technology. ${ }^{5}$ Letokhov predicted that the combination of multiple scattering and light amplification would lead to a form of laser action called random lasing. 6 In that case, the highly scattered nanostructured semiconductor materials with gain would be very attractive. Due to the wide band gap of $3.37 \mathrm{eV}$ and the large exciton binding energy of about $60 \mathrm{meV}$ at room temperature, $\mathrm{ZnO}$ has been recognized as a promising semiconductor material for numerous optoelectronics applications. ${ }^{7,8}$ In addition, recently it has been observed that nanostructured $\mathrm{ZnO}$ thin film exhibits very high optical nonlinear properties. ${ }^{9}$ Random laser effect is well studied experimentally in colloidal and microsized media. ${ }^{10,11}$ But studies in case of nanostructured materials are not so well advanced because of lack of pure and size controlled $\mathrm{ZnO}$ nanocluster materials. In this letter, we report the lasing effect in nanostuctured $\mathrm{ZnO}$ thin films under single or/and multiple photon excitation. There are several advantages of two-photon $(\lambda=700 \mathrm{~nm}, h \nu=1.77 \mathrm{eV})$ over single-photon $(\lambda=350 \mathrm{~nm}, h \nu=3.54 \mathrm{eV})$ pumping. First, two-photon excitation allows pumping over all sample thickness, ${ }^{12}$ while the light penetration depth is very short $\left(l_{\mathrm{abs}} \sim 100 \mathrm{~nm}\right)$ for the single-photon excitation (the absorption coefficient is measured to be about $\left.\alpha_{350 \mathrm{~nm}} \approx 10^{5} \mathrm{~cm}^{-1}\right) .{ }^{13}$ Second, excitation and emission wavelengths are too close and hard to separate in the case of single-photon pumping (350 and $385 \mathrm{~nm}$, respectively), whereas two-photon pumping wavelength is strongly distinct from the emission wavelength.

Zinc oxide nanoparticles with sizes ranging from 5 to $10 \mathrm{~nm}$ have been synthesized by pulsed laser ablation and deposited onto substrate heated up to $380{ }^{\circ} \mathrm{C}$. A detailed description of growth apparatus and structural characterizations is published earlier. ${ }^{14}$ Both transmission and photoluminescence spectra demonstrated high optical quality of $\mathrm{ZnO}$ nanoparticles. The fundamental absorption close to the edge at $392 \mathrm{~nm}$ and exciton peak position were detected at $3.29 \mathrm{eV}$. The films have, under low intensity $\mathrm{cw}$ excitation, an intense UV excitonic photoluminescence and a very weak

${ }^{a)}$ Electronic mail: marine@crmcn.univ-mrs.fr defect-related band that qualifies the film as having high quality.

Optical pumping was carried out using the output (700 and $350 \mathrm{~nm}$ ) of an optical parametric amplifier (OPA) and Ti:sapphire laser system $(800 \mathrm{~nm})$. Pulse durations were $t_{p}$ $=130$ and $100 \mathrm{fs}$, respectively. The pumping laser beam was focused by a spherical lens to form an excitation spot of radius ranging from 50 to $700 \mu \mathrm{m}$. The laser fluence was varied using either crossed polarizers or neutral filters. The emission was collected in a plane of the film into a slit of a spectrometer equipped with a charge coupled device detector. Lasing action was obtained using $350 \mathrm{~nm}$ (OPA) and both at $700 \mathrm{~nm}(\mathrm{OPA})$ and $800 \mathrm{~nm}$ (Ti:sapphire) pumping.

At threshold pumping intensity we observed the broad luminescence peak abruptly changing to a narrow lasing emission peak (see inset in Fig. 1). The emission intensity increased from the lasing threshold up to thermal degradation of the sample.

The results of single- and two-photon pumping of the same area of the film are shown in Fig. 1. The spot diameters are 100 and $90 \mu \mathrm{m}$, respectively. In the two-photon case at pumping fluences above $55 \mathrm{~mJ} / \mathrm{cm}^{2}$, we see a rapid growth of the emission peak at $3.23 \mathrm{eV}(\lambda=385 \mathrm{~nm})$. As the excitation intensity is increased from lasing threshold to damage level $\left(121 \mathrm{~mJ} / \mathrm{cm}^{2}\right)$ the output intensity increases ten times, the position of the emission peak shifted to $3.09 \mathrm{eV}$ $(402 \mathrm{~nm})$, and the spectral width increased from 25 to $92 \mathrm{meV}$ (full width at half maximum). The intensity dependence was approximated by an exponent function of pumping fluence for the single-photon pumping and of the square of the pumping fluence for the two-photon pumping. This sharp dependence can be provided by stimulated emission of photons both without and with feedback through scattering of emitted light. ${ }^{6}$ The mechanism of emission at high pumping fluence is combined from the exciton emission (EE) and the emission due to recombination of the electronhole plasma (EHP). ${ }^{15}$ The coexistence of these two emission regimes results probably from nonhomogeneous energy distribution in the pumping spot. At the highest excitation the peak of EHP of lasing spectrum is dominant. Thus, the curve in Fig. 1(b) can be divided into three regions: EE width changing at low fluences, a superposition of EE and EHP at 


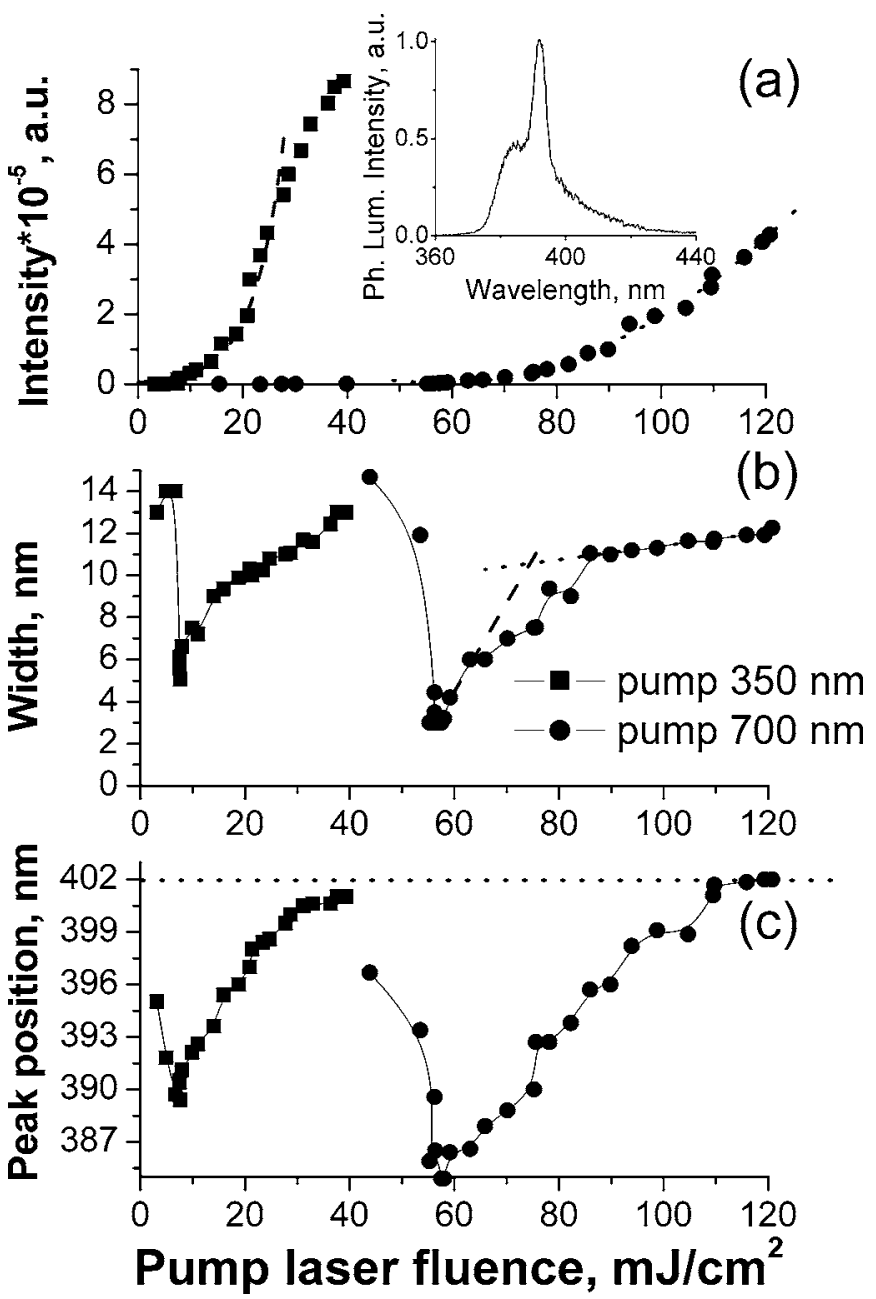

FIG. 1. Comparison of lasing emission characteristics from the same excited area of $\mathrm{ZnO}$ nanoparticle film for single- (ם) and two-photon (0) pumping as functions of pumping fluences: (a) lasing intensity, experimental points, and approximations; and (b) the width of lasing peak. The transitions from luminescence to lasing (solid line) and from exciton emission (dashed line) to electron-hole plasma recombination emission (dotted line) are shown. (c) Lasing peak position, whose evolution can be explained by band gap renormalization. Inset on (a) shows the narrow lasing emission peak superimposed on the broad luminescence peak. Pumping fluence was $55 \mathrm{~mJ} / \mathrm{cm}^{2}$ at $700 \mathrm{~nm}$.

intermediate fluences, and EHP broadening at the highest fluences. ${ }^{15}$

The curves of emission peak width versus excitation fluence demonstrate a well-defined threshold where the broad photoluminescence spectrum changes to a narrow lasing peak. Both the wavelength, at which lasing starts, and the initial emission peak width are less for two-photon pumping [Figs. 1(c) and 1(b)] than for single-photon pumping of the same area on the film.

In both cases, as is shown in Fig. 1(c), when increasing the pumping fluence the spectral position of the lasing peak shifts from exciton emission wavelength to longer wavelengths due to a band gap renormalization and EHP emission. $^{16}$

Two-photon excitation provides a possibility to realize transmission experiment in parallel to lasing. As pumping pulse duration is much shorter than the characteristic time of lasing emission, ${ }^{17}$ thus lasing should not influence the transmission. Figure 2 demonstrates the experimental dependence of the $\mathrm{ZnO}$ nanocluster film transmission on pump intensity.

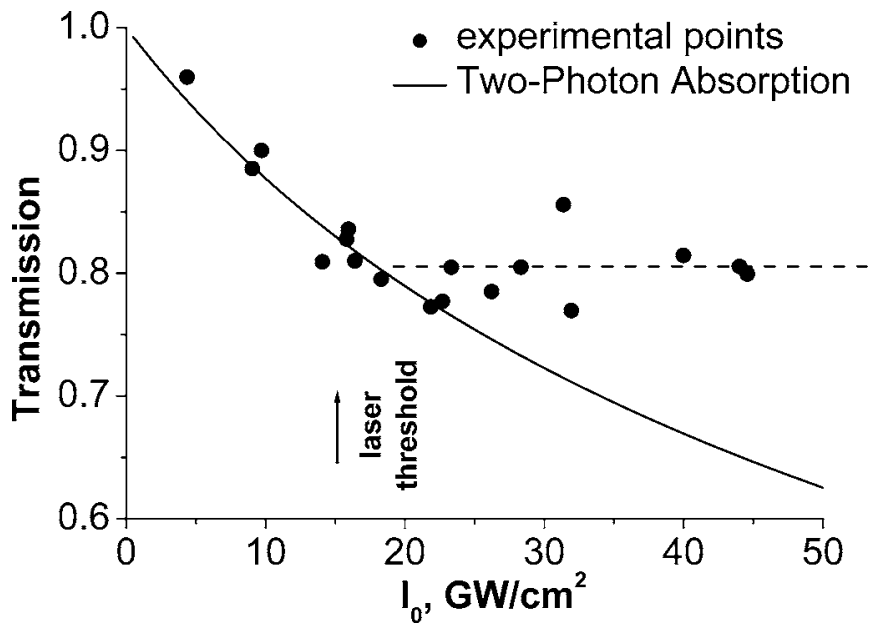

FIG. 2. Experimental and theoretical nonlinear transmission curves at $700 \mathrm{~nm}$. The arrow indicates lasing threshold.

The spot diameter is $350 \mu \mathrm{m}$. The analytically obtained dependence of transmission of two-photon absorbing film on pump laser intensity is a hyperbolic function. ${ }^{18}$ The fit between experimental and theoretical curves may be considered satisfactory only at low excitation intensities $I_{0}$ $<20 \mathrm{GW} / \mathrm{cm}^{2}$. The two-photon absorption coefficient $\beta$ at $700 \mathrm{~nm}$ was adjusted to provide the best fit of the theoretical curve to the experimental data. As a result, $\beta_{700}$ is about $450 \mathrm{~cm} / \mathrm{GW}$; this value is higher than the ones measured earlier under nanosecond and picosecond excitations. ${ }^{19,20}$ In the case of transmission measurements at $800 \mathrm{~nm}$, the effective two-photon absorption coefficient was estimated to be $\beta_{800} \approx 110 \mathrm{~cm} / \mathrm{GW}$.

It should be noted, however, that along with the twophoton absorption mechanism through a virtual level, the two-step absorption through low impurity level can be considered. As is seen in Fig. 2, at high intensities, the saturation of transmission occurs revealing, thereby, the saturation of corresponding transition.

Figure 3 shows the experimental results of lasing threshold dependence on spot size under single- and two-photon

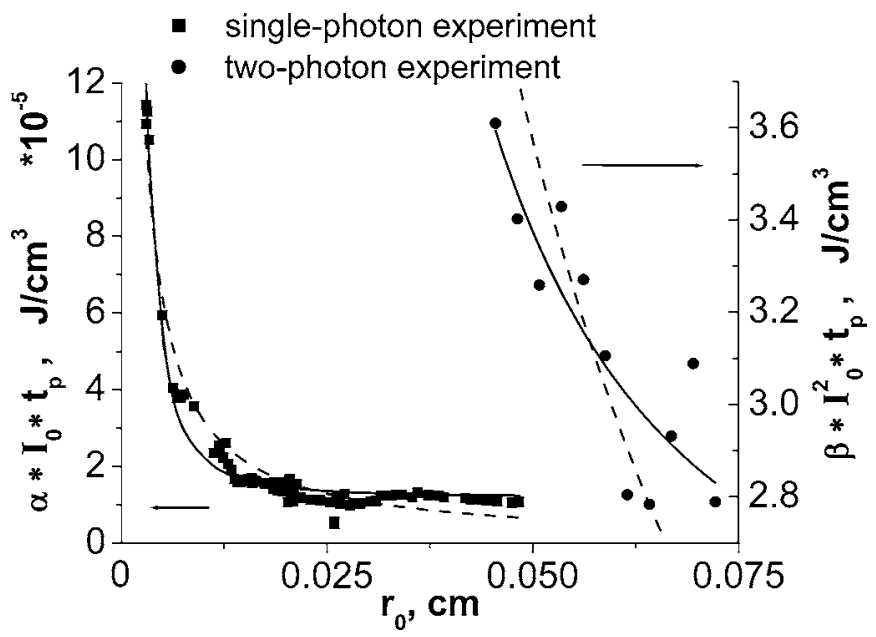

FIG. 3. Lasing threshold vs pumping beam radius: (ם) single-photon pumping and (-) two-photon pumping. Ordinate shows a threshold volume density of absorbed energy per pulse. $\alpha, \beta$, and $t_{p}$ are single- and two-photon absorption coefficients and laser pulse duration, respectively. Fitting related to light propagation in disordered media with gain and amplified spontaneous emission shown by continuous and dashed lines, respectively. 
pumping and the corresponding theoretical approximations. It can be clearly seen that the threshold gain strongly increases with decreasing excitation spot area. ${ }^{11,21}$ However, it should be noted that this behavior is typical for amplified spontaneous emission whether or not the feedback through scattering of emitted light is involved. In Fig. 3 we compare the corresponding experimental data with theoretical predictions for two limiting cases. It is seen that the dependence of the threshold gain on the excitation spot radius $r_{0}$ is closer to the $\left(1 / r_{0}^{2}\right)$ than to the $\left(1 / r_{0}\right)$ approximation. The former function corresponds to a description of emitted light propagation by the diffusion equation with gain (disordered media). It is shown, for instance, for a plain disordered film surrounded by the media with other refractive indices for the case of multiple-photon pumping. ${ }^{22}$ If $\left(1 / r_{0}\right)$ dependence is valid, it provides no scattering at all. Thus the experimental results suggest that the role of light scattering in our case is significant.

Experimentally we observe that, at lasing threshold, the increasing pulse duration of a pumping beam at fixed pulse energy leads to the increase of spot radius. The gain is determined by the population inversion, which is proportional to the volume density of absorbed pump power. ${ }^{12}$ In the case of single-photon pumping it means that the gain is proportional to laser fluence $\left(g_{\text {th }} \sim \alpha \times f=\alpha \times I_{0} \times t_{p}\right)$. In case of two-photon pumping only approximation $g_{\text {th }} \sim I_{0}^{2} \times t_{p}$ but not $g_{\mathrm{th}} \sim I_{0}^{2} \times t_{p}^{2}$ provides experimentally observed decrease of the pumping gain while increasing $r_{0}$ (see Fig. 3). The fact that the volume density of absorbed pump power in this case is proportional to $I_{0}^{2} \times t_{p}$ suggests a coherent nature of the corresponding two-photon transition.

In conclusion, high quality nanostuctured $\mathrm{ZnO}$ thin films were prepared by the pulsed laser ablation method. We observed the lasing effect under two-photon femtosecond laser excitation of $\mathrm{ZnO}$ thin films. Our experiments show that the feedback provided by scattering of emitted light is involved in two-photon-induced lasing effect. This effect reveals that the $\mathrm{ZnO}$ nanoparticles show useful properties and potential applications in nanophotonics fields.
This work was supported by the French program "Réseau: Formation-Recherche, Europe Centrale et Orientale," the Program of presidium of the Russian Academy of Sciences "Femtosecond Optics and Physics of Superstrong Laser Fields," and RFBR Grant Nos. 05-02-08151-ofi_a and 06-02-17381-a.

${ }^{1}$ Zh. Fan and J. G. Lu, J. Nanosci. Nanotechnol. 5, 1561 (2005).

${ }^{2}$ Y. Gu, I. L. Kuskovsky, M. Yin, S. O'Brien, and G. F. Neumark, Appl. Phys. Lett. 85, 3383 (2004).

${ }^{3}$ S. R. Quake and A. Scherer, Science 290, 1536 (2000).

${ }^{4}$ L. Mazzola, Nat. Biotechnol. 21, 1137 (2003).

${ }^{5}$ D. Wiersma, Nature (London) 406, 132 (2000).

${ }^{6}$ V. S. Letokhov, Sov. Phys. JETP 26, 835 (1968).

${ }^{7}$ Y. W. Heo, L. C. Tien, Y. Kwon, D. P. Norton, S. J. Pearton, B. S. Kang, and F. Ren, Appl. Phys. Lett. 85, 2274 (2004).

${ }^{8}$ N. W. Emanetoglu, J. Zhu, Y. Chen, J. Zhong, Y. M. Chen, and Y. C. Lu, Appl. Phys. Lett. 85, 3702 (2004).

${ }^{9}$ G. I. Petrov, V. Shcheslavskiy, V. V. Yakovlev, I. Ozerov, E. Chelnokov, and W. Marine, Appl. Phys. Lett. 83, 3993 (2003).

${ }^{10}$ X. H. Wu, A. Yamilov, H. Noh, H. Cao, E. W. Seelig, and R. P. H. Chang, J. Opt. Soc. Am. B 21, 159 (2004).

${ }^{11}$ Y. Ling, H. Cao, A. L. Burin, M. A. Ratner, X. Liu, and R. P. H. Chang, Phys. Rev. A 64, 063808 (2001).

${ }^{12}$ A. L. Burin, H. Cao, and M. A. Ratner, IEEE J. Sel. Top. Quantum Electron. 9, 124 (2003).

${ }^{13}$ N. R. Aghamalyan, E. A. Kafadaryan, R. K. Hovsepyan, and S. I. Petrosyan, Semicond. Sci. Technol. 20, 80 (2005).

${ }^{14}$ I. Ozerov, D. Nelson, A. V. Bulgakov, W. Marine, and M. Sentis, Appl. Surf. Sci. 212-213, 349 (2003).

${ }^{15}$ V. S. Dnepropetrovskiy, V. I. Klimov, and M. G. Novikov, JETP Lett. 51, 219 (1990).

${ }^{16}$ A. Yamamoto, T. Kido, T. Goto, Y. F. Chen, and T. Yao, Solid State Commun. 122, 29 (2002).

${ }^{17}$ Y. H. Leung, W. M. Kwok, A. B. Djurřsíc, D. L. Phillips, and W. K. Chan, Nanotechnology 16, 579 (2005).

${ }^{18}$ V. L. Bredikin, M. D. Galanin, and V. N. Genkin, Usp. Fiziol. Nauk 110, 3 (1973).

${ }^{19}$ I. M. Catalano, A. Cingolani, and M. Lepore, Phys. Rev. B 33, 7270 (1986).

${ }^{20}$ J. Collet and T. Amand, Phys. Rev. B 33, 4129 (1986).

${ }^{21}$ D. Anglos, A. Stassinopoulos, R. Das, G. Zacharakis, M. Psyllaki, R. Jaku-biak, R. Vaia, E. Giannelis, and S. Anastasiadis, J. Opt. Soc. Am. B 21, 208 (2004).

${ }^{22}$ E. V. Chelnokov, N. M. Bityurin, and W. Marine, Proc. SPIE 5975, 229 (2006). 
Applied Physics Letters is copyrighted by the American Institute of Physics (AIP). Redistribution of journal material is subject to the AIP online journal license and/or AIP copyright. For more information, see http://ojps.aip.org/aplo/aplcr.jsp 